\title{
Feasibility study of SR-TXRF-XANES analysis for iron contaminations on a silicon wafer surface
}

\author{
F. Meirer, ${ }^{a *}$ C. Streli, ${ }^{a}$ G. Pepponi, ${ }^{b}$ P. Wobrauschek, ${ }^{\text {a }}$ M. A. Zaitz, ${ }^{c}$ \\ C. Horntrich ${ }^{a}$ and G. Falkenberg ${ }^{d}$
}

The ability to chemically characterize the contamination on silicon wafers is of critical importance to the semiconductor industry. It provides information on possible unwanted chemical processes taking place on the wafer surface and helps in determining the true source of the contamination problem. This type of information is not readily accessible with standard laboratory equipment. Synchrotron radiation-induced total reflection X-ray fluorescence (SR-TXRF) was combined with X-ray absorption near-edge structure (XANES) to determine the chemical state of Fe contaminations on a silicon wafer surface. Main purpose of the study was to test the method for a contamination issue as it could appear in a microelectronic VLSI production fab. Copyright (c) 2008 John Wiley \& Sons, Ltd.

Keywords: SR-TXRF; TXRF-XANES; wafer surface analysis

\section{Introduction}

Iron contaminations on the surface of Si wafers are known to be a serious limiting factor to yield and reliability of complementary metal oxide semiconductor (CMOS) based integrated circuits. ${ }^{[1]}$ Total reflection X-ray fluorescence (TXRF) is a widespread analytical technique for the monitoring of surface contamination on nonpatterned wafers in the semiconductor industry. ${ }^{[2,3]}$ In laboratory-based instruments it offers detection limits down to the 5 E9 at $/ \mathrm{cm}^{2}{ }^{\left[{ }^{[4]}\right.}$ When higher sensitivity is requested, monitoring is typically carried out by vapor phase decomposition (VPD) of the native oxide layer and analysis by means of laboratory-based TXRF and/or inductively coupled plasma mass spectrometry (ICP-MS) on the expense of the loss of the information relative to the location and distribution of the contamination on the wafer. ${ }^{[2,3,5-7]}$ For tracing the source of the contamination not only the distribution of the contamination is very valuable but also additional information on the chemical state of the element can be helpful. Understanding the chemical state is important to gain information on the source of contamination: if more metallic in nature the contamination could be particles from wear or shearing of moving parts; if the iron is an oxide, corrosion may be taking place. Other species may indicate unexpected chemical reactions, which take place.

Synchrotron radiation-induced TXRF (SR-TXRF) is a microanalytical technique which offers sensitivities as high as $8000 \mathrm{cps} / \mathrm{ng}$ and detection limits in the $\mathrm{fg}$ range for transition metals with a multilayer monochromator and a bending magnet beamline. ${ }^{[8-11]}$ With a crystal monochromator the technique can be coupled to X-ray absorption spectroscopy (XAS) to gain information on the chemical environment of the specific elements of interest. With this modified setup there is a flux reduction of about two orders of magnitude, but it is still sufficient for X-ray absorption near-edge structure (XANES) analysis at ppb level. ${ }^{[12-15]}$

The presented study was motivated by the question whether the known low concentrations of contaminations on the surface of a Si wafer are sufficient for a SR-TXRF analysis using a Si(111) monochromator including a XANES analysis within a reasonable time frame. Therefore, one aim of the study was to perform the measurements on the points of interest within $48 \mathrm{~h}$.

\section{Experimental}

A Si wafer from IBM laboratories showing surface contaminations in the $4 \mathrm{E} 12 \mathrm{at} / \mathrm{cm}^{2}$ range for Fe has been investigated. The contaminations were not intentionally prepared, but real contaminations due to fabrication processes. SR-TXRF XANES measurements were performed at the bending magnet beamline $L$ at HASYLAB using a modified micro-XRF setup. This modified setup allowed TXRF measurements with scanning capability. The Wafer with $200 \mathrm{~mm}$ diameter was mounted vertically on a custom-made holder on a $x, y, z, \theta$-stage in front of the side-looking detector to allow area scans and scans over the angle of incidence. The distance between sample and detector was set to $1 \mathrm{~mm}$. A laminar flow hood is present on the setup at HASYLAB to prevent contamination during the measurement. The $\mathrm{Si}(111)$ double crystal monochromator was used and a silicon drift detector (SDD) with $50 \mathrm{~mm}^{2}$ active area (VORTEX $50 \mathrm{~mm}^{2}$, Radiant Detector Technologies) ${ }^{[16]}$ for the detection of the fluorescence radiation. The beam dimensions were adjusted to $1600 \times 400 \mu \mathrm{m}$ (vertical $\times$ horizontal). All measurements were performed in air.

For the XANES measurements the excitation energy was tuned from 6950 to $7800 \mathrm{eV}$ in varying steps $(10-0.5 \mathrm{eV})$ across the iron $\mathrm{K}$ edge at $7111 \mathrm{eV}$. The acquisition time for each spectrum was set

\footnotetext{
* Correspondence to: F. Meirer, Atominstitut, TU-Wien, A-1020 Vienna, Austria E-mail:fmeirer@ati.ac.at

a Atominstitut, TU-Wien, A-1020 Vienna, Austria

b Fondazione Bruno Kessler, via Sommarive 18, 38100 Povo (Trento), Italy

c IBM Microelectronics, Hopewell Junction, New York, NY, USA

d Hamburger Synchrotronstrahlungslabor at DESY, 22607 Hamburg, Germany
} 

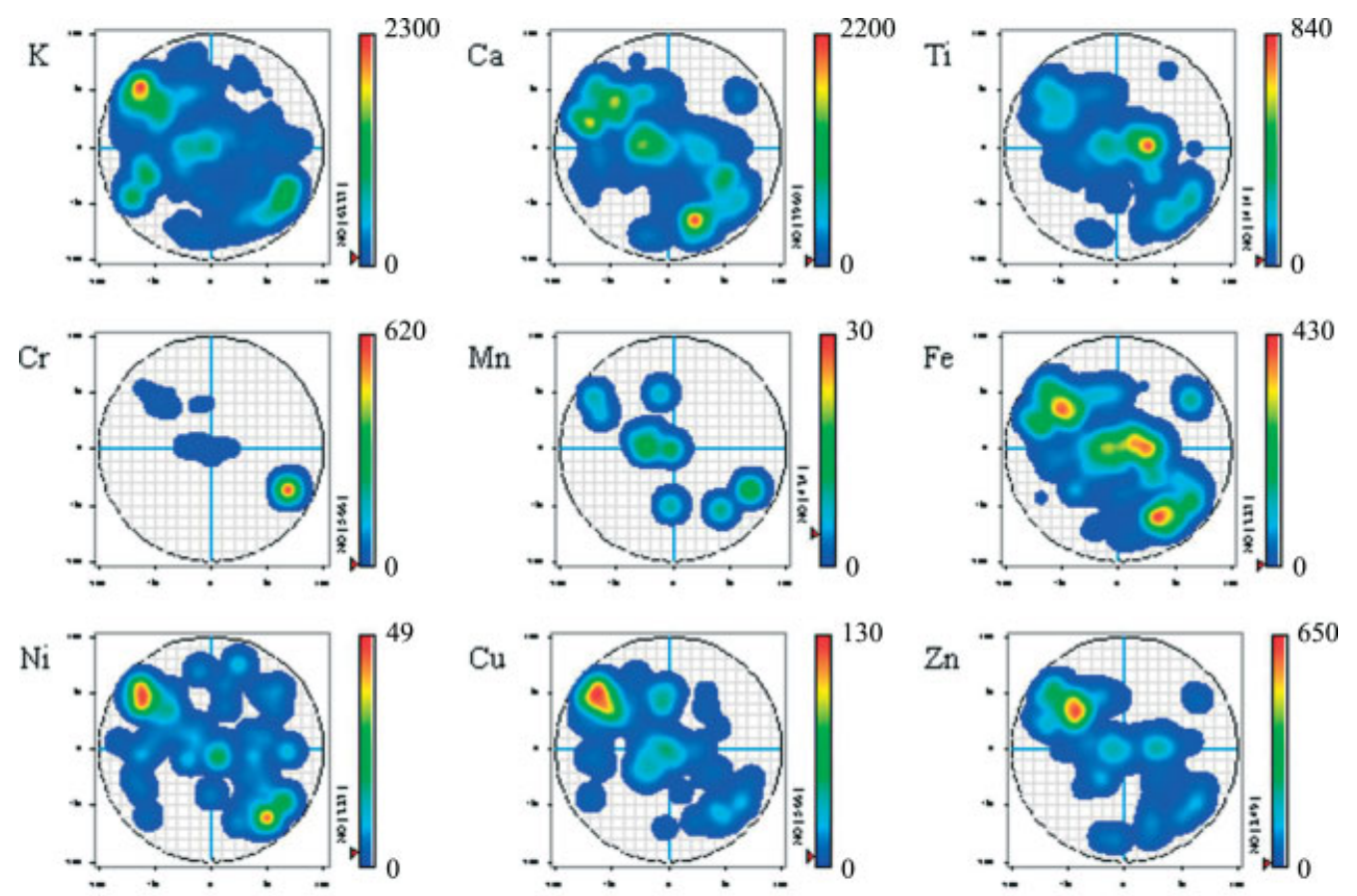

Maps of elemental distribution on $200 \mathrm{~mm}$ Si-Wafer

Map: 229 points X-Ray: $30 \mathrm{kV} 300 \mathrm{~mA}$ Beam: W-L $\beta$ Sampletime: $5 \mathrm{sec}$ Scale: E10 atoms $/ \mathrm{cm}^{2}$

Figure 1. Maps of the contaminations on the $200-\mathrm{mm}$ wafer measured with a laboratory TXRF wafer-analyzer.
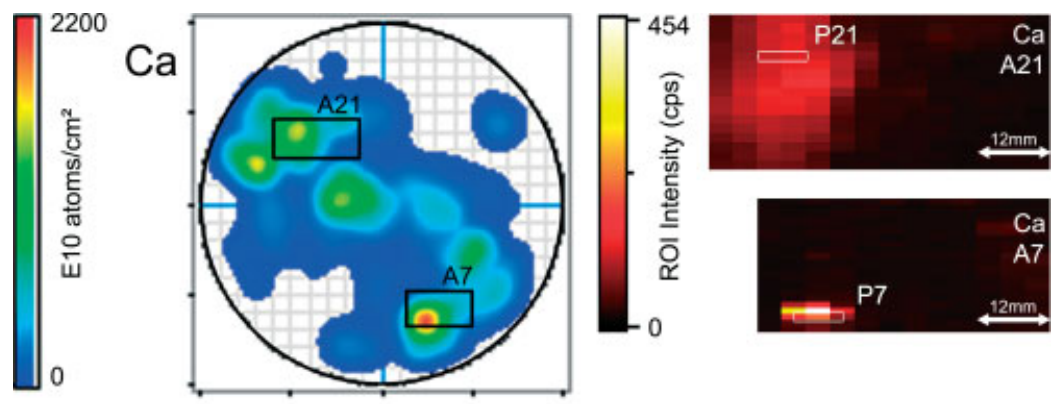

(a)

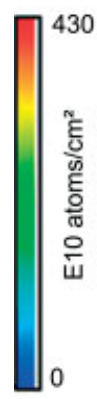

(b)

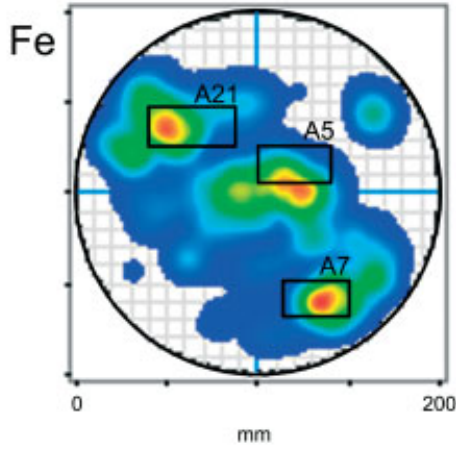

$\mathrm{mm}$
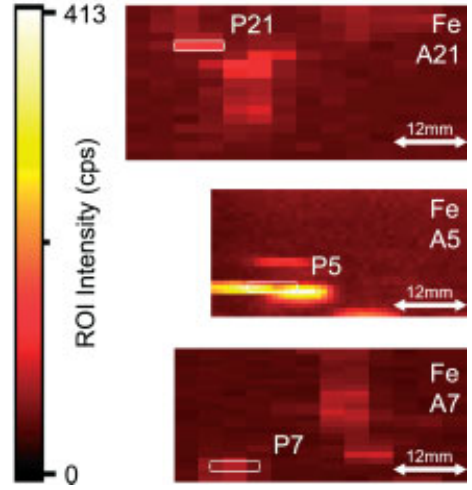

Figure 2. Laboratory TXRF maps (a) with marked regions of the areas scanned by means of SR-TXRF (b). The marked regions on the left correspond to the areas on the right. The white boxes on the right localize the points of maximum Fe contamination which were selected for further investigations (P21, P5, and P7). 
to $5 \mathrm{~s}$ for sample position P5 and P7 and $8 \mathrm{~s}$ for sample position P21. Including the time needed for motor movements during the scan the overall time for one scan (454 spectra) accumulated to $\sim 50$ min for P5 and P7 and 75 min for P21. For each specimen at least three repetitive scans were performed to increase the signalto-noise ratio. During all XANES measurements the absorption of an iron foil was recorded in transmission mode simultaneously. The first inflection point (i.e. the first maximum of the derivative of the spectrum) of the Fe metal foil scan was assumed to be $7111 \mathrm{eV}$ (Fe-K edge). The energy scale of each XANES scan (standards and samples) was corrected with respect to the Fe-K edge.

The peak fitting of the fluorescence spectra was done within the software package QXAS ${ }^{[17]}$ and the absorption spectra have been analyzed using ATHENA of the IFEFFIT software package. ${ }^{[18-20]}$ ATHENA was also used for the linear combination fitting procedure.

The experimental setup, testing, and all measurements were accomplished within $48 \mathrm{~h}$.

\section{Results and Discussion}

Figure 1 shows the contamination maps on the 200-mm Si wafer obtained with a laboratory TXRF instrument; three areas are marked and labeled (A5, A7, and A21). The TXRF instrument is a Rigaku TXRF 3003 crystal system with an 18-kW generator. The system can measure $\mathrm{K}$ line series for elements from $\mathrm{Na}, \mathrm{Al}$, and $\mathrm{Mg}$ through the transition series to heavy elements such as Mo. For quantification the instrument was calibrated with a reference standard sample provided by the manufacturer. The strength of the instrument is the full-wafer-mapping software which was designed as a fast analysis highlighting very high points or repeatable patterns of contamination. There are several papers on the statistics of the analysis. ${ }^{[21,22]}$

Figure 2 shows the Ca and Fe maps of the marked areas carried out with SR-TXRF. The steps of the grid for the surface scan were matched to the size of the collimator of the detector $(8 \mathrm{~mm}$ in diameter) and the vertical beam dimension $(1.6 \mathrm{~mm})$. The Ca map is shown as an example of how the maps of the other elements were used to double-check that the correct position of interest was found. Because of the limited time frame of the measurements the area scan A5 was stopped after finding a first maximum of iron contaminations. The marked positions (P5, P7, and P21) have been chosen for further investigations.

Angular scans at these positions have shown that all contaminations are present in the form of residue on the wafer surface. This is indicated by the typical angular intensity curve ${ }^{[23]}$ of the Fe-K $\alpha$ fluorescence diagram as in Fig. 3.

A spectrum of each point of interest was recorded for $100 \mathrm{~s}$. Figure 4 shows the fluorescence spectrum recorded at position P5. The energy of the incident beam was set to $7800 \mathrm{eV}$ for these measurements. The limit of detection for a measurement time of $100 \mathrm{~s}$ (LD100) for Fe was estimated from these measurements to be in the range of $750 \mathrm{fg}$. The LD was calculated using:

$$
\mathrm{LD}=\frac{3 \cdot \sqrt{N_{B}}}{N_{N}} \times m_{\text {sample }}
$$

where $m_{\text {sample }}$ was calculated to $\sim 45 \mathrm{pg}$ using the data obtained in the laboratory measurements $\left(\sim 400\right.$ E10 atoms $\left./ \mathrm{cm}^{2}\right)$ and assuming an inspected area of $1.6 \times 8 \mathrm{~mm}^{2}$. The LD values for a measurement time of $1000 \mathrm{~s}$ (LD1000) have been extrapolated to $250 \mathrm{fg}$. The peak-to-background ratios were found to be 12.6, 9.3, and 3.5 for $\mathrm{P} 5, \mathrm{P} 21$, and $\mathrm{P} 7$ respectively.

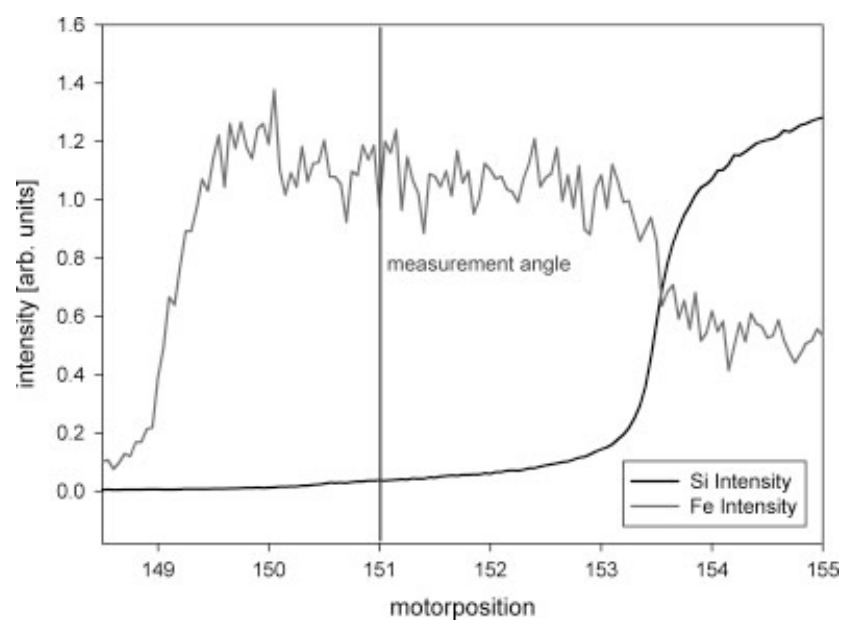

Figure 3. Intensity versus angle of incidence (position of rotator $\theta$ ) recorded at position P5.

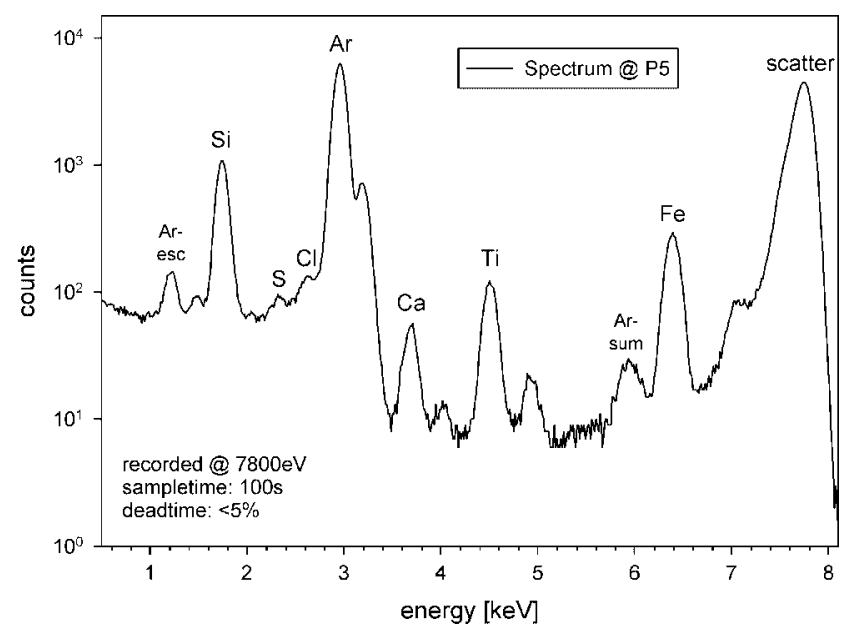

Figure 4. Fluorescence spectrum recorded by SR-TXRF for 100 s at position P5.

Fe-K edge XANES measurements have been carried out in the positions indicated. For each position at least three repetitions were performed. Repetitive scans have been merged together to improve the signal-to-noise ratio. For the speciation the spectra obtained from the unknown contamination must be compared with spectra of possible reference materials. If the contamination is completely unknown a reliable determination of the compound might not be possible and the investigator must be satisfied with a qualitative indication about the oxidation state of the element examined. Reference samples of common iron species have been measured in vacuum under TXRF conditions ${ }^{[14]}$ for comparison. Figure 5 shows all measured Fe standards. The number of standards measured is certainly a key factor in the tradeoff between overall time of investigation and quality of the results or even success or failure.

Table 1 presents the determined edge positions (first inflection point of the XANES spectra) and the oxidation states of all measured standards and samples. The Fe oxidation states of the samples have been determined by comparison with the standards. 


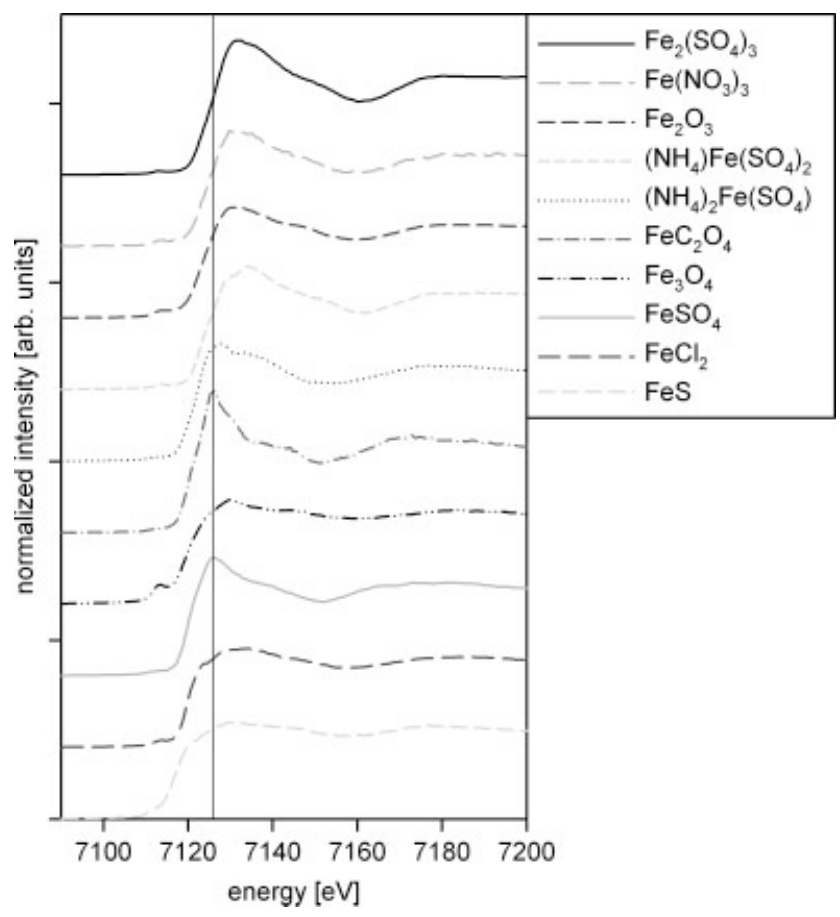

Figure 5. All measured Fe-standards. The vertical line at $7126 \mathrm{eV}$ indicates the edge position of the ferric sulfate $\left(\mathrm{Fe}_{2}\left(\mathrm{SO}_{4}\right)_{3}\right)$ standard.

Table 1. Oxidation states and edge positions of standards and locations analyzed on the Si wafer

\begin{tabular}{|c|c|c|}
\hline & Compound & Edge position (eV) \\
\hline $\mathrm{FeS}$ & Iron(II)-sulfide & 7117 \\
\hline $\mathrm{FeCl}_{2}$ & Iron(II)-chloride & 7119 \\
\hline $\mathrm{FeSO}_{4}$ & Iron(II)-sulfate & 7119.5 \\
\hline $\mathrm{Fe}_{3} \mathrm{O}_{4}$ & Iron(II,III)-oxide & 7119.5 \\
\hline $\mathrm{FeC}_{2} \mathrm{O}_{4}$ & Iron(II)-oxalate & 7120.5 \\
\hline$\left(\mathrm{NH}_{4}\right)_{2} \mathrm{Fe}\left(\mathrm{SO}_{4}\right)_{2}$ & Ammonium-iron(II)-sulfate & 7122.5 \\
\hline $\mathrm{NH}_{4} \mathrm{Fe}\left(\mathrm{SO}_{4}\right)_{2}$ & Ammonium-iron(III)-sulfate & 7123 \\
\hline $\mathrm{Fe}_{2} \mathrm{O}_{3}$ & Iron(III)-oxide & 7123.5 \\
\hline $\mathrm{Fe}\left(\mathrm{NO}_{3}\right)_{3}$ & Iron(III)-nitrate & 7125 \\
\hline $\mathrm{Fe}_{2}\left(\mathrm{SO}_{4}\right)_{3}$ & Iron(III)-sulfate & 7126 \\
\hline Wafer at P5 & $\mathrm{Fe}(\mathrm{III})$ & 7125 \\
\hline Wafer at P7 & $\mathrm{Fe}(\mathrm{II})$ & 7121.5 \\
\hline Wafer at P21 & $\mathrm{Fe}(\mathrm{III})$ & 7124.5 \\
\hline
\end{tabular}

Figure 6 shows the XANES spectra for the three points analyzed along with the spectra of the standards with their edge positions closest to the edge positions of the samples.

The XANES spectra were recorded summing all counts within the Fe-Ka region-of-interest (ROI). To make sure that this method is reliable for such low concentrations one XANES scan of each point (P5, P7, and P21) was generated using the net-intensity of the Fe-Ka peak. Each fluorescence spectrum of the scan was therefore fitted with QXAS. A comparison of the XANES spectra revealed no significant differences between the scans generated in the two mentioned ways. The apparent discrepancy was the increased signal in the low energy range of the preedge region of the scan generated using the ROI method. This effect can be explained by a contribution of the scatter peak increasing the
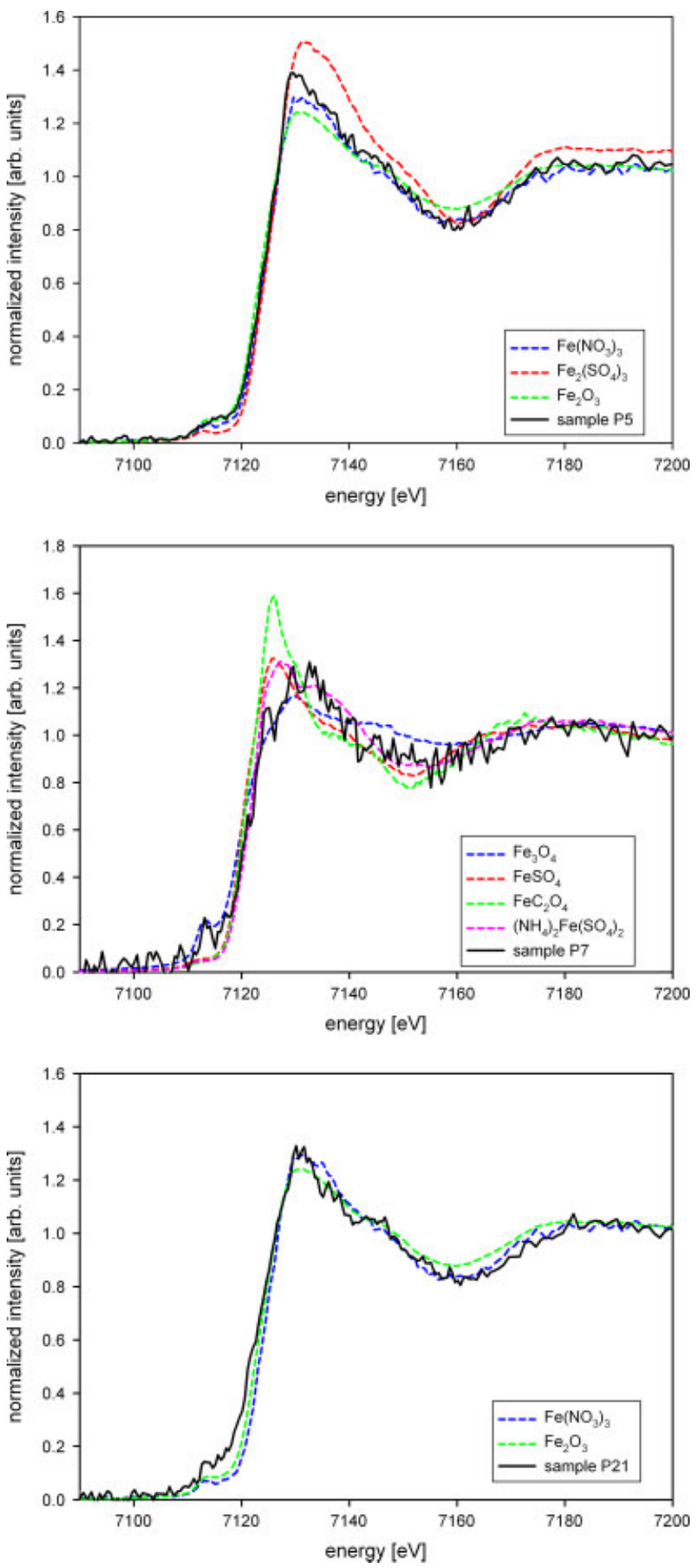

Figure 6. XANES scans at positions P5, P7, and P21 in comparison with the spectra of the standards with similar edge positions. This figure is available in colour online at www.interscience.wiley.com/journal/sia.

counts of the $\mathrm{Fe}-\mathrm{Ka} \mathrm{ROI}$ at low energies far below the edge. However, as the signal-to-noise ratio was not improved using the peak fitting method the ROI evaluation was used.

The poor counting statistic for P7 and P21 made the results of further investigations of the Fe-compound on the wafer's surface doubtful. For P5 it was possible to perform linear combination fits to have an estimation of the composition of the Fe contamination. 
Table 2. Results and fit parameters of the best fit for P5 $\mathrm{Fe}_{2} \mathrm{O}_{3} \quad \mathrm{Fe}\left(\mathrm{NO}_{3}\right)_{3} \quad \mathrm{Fe}_{2}\left(\mathrm{SO}_{4}\right)_{3}$ (\%) (\%)

$R$-factor

Chi-square

P5 $26 \pm 7$

$48 \pm 8$

$26 \pm 10$

0.001424

0.1478

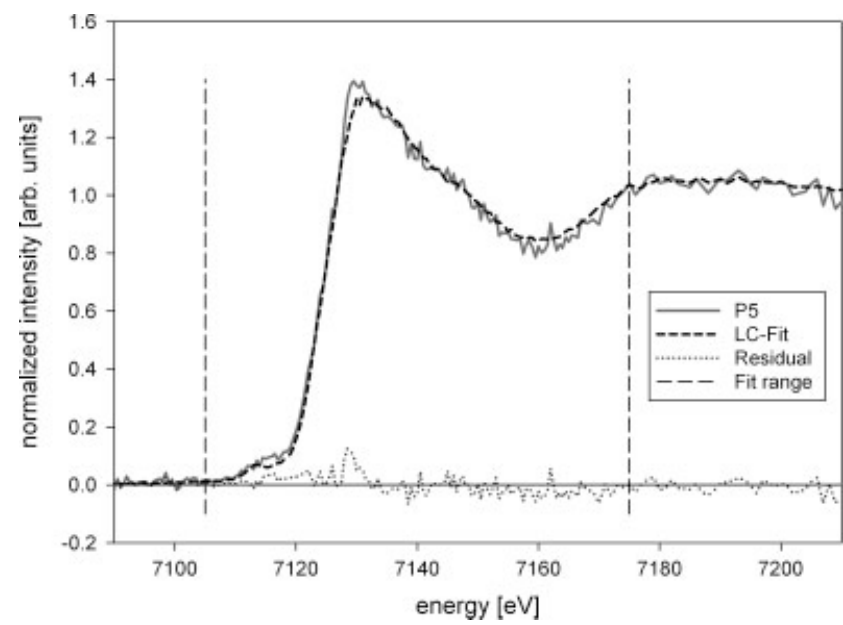

Figure 7. Result of the best linear combination fit for sample P5.

The three most appropriate (Fig. 6) standards $\left[\mathrm{Fe}_{2} \mathrm{O}_{3}, \mathrm{Fe}\left(\mathrm{NO}_{3}\right)_{3}\right.$, and $\mathrm{Fe}_{2}\left(\mathrm{SO}_{4}\right)_{3}$ ] were used for a linear combination fit using all possible combinations (4) of these standards. The results and fit parameters of the best fit (best $R$-factor) are reported in Table 2 . The $R$-factor was determined using:

$$
R=\frac{\sum(\text { data }-\mathrm{fit})^{2}}{\sum(\text { data })^{2}}
$$

Figure 7 shows the result of the best linear combination fit for sample P5.

\section{Conclusions}

It could be shown that SR-TXRF in combination with XAS enables a XANES analysis of wafer surface contaminations even in the pg region within a reasonable time frame. The setup allows a spatially resolved multielement analysis of the wafers surface. Additionally the type of the contamination (residual, surface layer, and bulk) and the chemical state of a specific element can be determined. All these investigations can be done nondestructively using the same experimental setup. The major problem of this setup is the measurement time and the need for an intense and energy tunable X-ray source. The wafer mapping and XANES scans are time consuming particularly for such low concentrations. The XANES evaluation showed that a peak to background ratio below ten for the element of interest in the fluorescence spectra will cause serious problems for the interpretation of the data. Within the time frame of $48 \mathrm{~h}$, three points of interest could be investigated. A determination of the oxidation state of iron in the samples was possible. However, for the determination of the iron compound satisfactory results could be achieved for only one point (P5). The evaluation of the other points (P7, P21) with the linear combination fit procedure was not satisfying due to the low Fe concentrations and the limited measurement time resulting in a poor signal-tonoise ratio of the XANES spectrum. The preedge peak intensity of an XANES spectrum of a $3 \mathrm{~d}$ transition metal generally depends on its coordination number. Therefore it is reasonable to evaluate this region. However, a detailed analysis of the prepeak of the XANES spectra suffers even more from high noise levels because the preedge region generally shows a much lower signal than the fine structure above the edge. A reliable, detailed analysis was therefore not possible.

The evaluation of the XAS data revealed that the iron contamination in point P5 is a mixture of iron compounds dominated by iron-nitrate. Although the evaluation for P5 showed a low statistical uncertainty it cannot be concluded that the contamination is a mixture of iron-nitrate and iron-sulfate exclusively. Within the frame of this feasibility study it was not possible to compare the Fe contaminations with every possible Fe compound. However, the presence of iron-nitrate and iron-sulfate on a contaminated wafer shows that several chemical reactions are taking place. The iron-sulfate is particularly surprising and we are trying to better determine why or how it was formed. This will be topic of further investigations.

\section{Acknowledgements}

The authors would like to thank U. E. A. Fittschen who provided the Fe standards. This work was supported by the Austrian Science Fund (FWF), project number P18299, and the European Commission, project number II-20042060. This study was done within the frame of CRP (G4.20.02./1271) 'Unification of nuclear spectrometries: integrated techniques as a new tool for material research.'

\section{References}

[1] A. A. Istratov, H. HiesImair, E. R. Weber, Appl. Phys. A: Mater. Sci. Process. 2000, 70, 5489.

[2] P. Wobrauschek, X-Ray Spectrom. 2007, 36, 5289.

[3] S. Pahlke, L. Fabry, L. Kotz, C. Mantler, T. Ehmann, Spectrochim. Acta, Part B: At. Spectrosc. 2001, 56, 112261.

[4] The Technos international homepage, www.technosintl.com/trex630.php, 2008.

[5] The Rigaku homepage, www.rigaku.com/semi/txrf-v300.html, 2008.

[6] L. Fabry, S. Pahlke, L. Kotz, G. Tölg, Fresenius J. Anal. Chem. 1994, $349,4260$.

[7] G. Settembre, E. Debrah, Micro 1998, 16, 679.

[8] P. Wobrauschek, P. Kregsamer, W. Ladisich, C. Streli, S. Pahlke, L. Fabry, S. Garbe, M. Haller, A. Knochel, M. Radtke, Nucl. Instrum. Methods Phys. Res., Sect. A 1995, 363, 3619.

[9] P. Pianetta, N. Takaura, S. Brennan, W. Tompkins, S. S. Laderman, A. Fischer-Colbrie, A. Shimazaki, K. Miyazaki, M. Madden, D. C. Wherry, J. B. Kortright, Rev. Sci. Instrum. 1995, 66, 2 1293.

[10] F. Comin, M. Navizet, P. Mangiagalli, G. Apostolo, Nucl. Instrum. Methods Phys. Res., Sect. B 1999, 150, 1-4 538.

[11] P. Pianetta, K. Baur, A. Singh, S. Brennan, J. Kerner, D. Werho, J. Wang, Thin Solid Films 2000, 373, 1-2 222.

[12] A. Singh, K. Baur, S. Brennan, T. Homma, N. Kubo, P. Pianetta, X-Ray Absorption Spectroscopy on Copper Trace Impurities on Silicon Wafers, MRS Proceedings 2002, 716, 23.

[13] G. Falkenberg, G. Pepponi, C. Streli, P. Wobrauschek, Spectrochim. Acta, Part B: At. Spectrosc. 2003, 58, 122239.

[14] C. Streli, G. Pepponi, P. Wobrauschek, C. Jokubonis, G. Falkenberg, G. Zaray, X-Ray Spectrom. 2005, 34, 5451.

[15] F. Meirer, G. Pepponi, C. Streli, P. Wobrauschek, V. G. Mihucz, G. Záray, V. Czech, J. A. C. Broekaert, U. E. A. Fittschen, G. Falkenberg, $X$-Ray Spectrom. 2007, 36, 6408. 
[16] The SII nanotechnology incorporated website, www.radiant detectors.com/vortex.html, 2007.

[17] The IAEA homepage, www.iaea.or.at/programmes/ripc/physics/ faznic/qxas.htm., 2007

[18] The IFEFFIT homepage, http://cars9.uchicago.edu/ifeffit/, 2007.

[19] M. Newville, J. Synchrotron Radiat. 2001, 8, 2322.

[20] B. Ravel, M. Newville, J. Synchrotron Radiat. 2005, 12, 4537.
[21] Y. Mori, K. Uemura, Y. lizuka, Anal. Chem. 2002, 74, 51104.

[22] Y. Mori, K. Uemura, H. Kohno, M. Yamagami, T. Yamada, K. Shimizu, Y. Onizuka, Y. lizuka, Spectrochim. Acta, Part B: At. Spectrosc. 2004, $59,81277$.

[23] H. Schwenke, J. Knoth, Total reflection XRF, Handbook of X-ray Spectrometry, R.E. Van Griecken, A.A. Markowicz (Eds), Methods and Techniques, Marcel Dekker, New York, 1993, 453. 